\title{
A Survey of Perspectives and Factors in the Development of Medical Tourism in the Middle East
}

\author{
Fatemeh Hosseini ${ }^{1}$ and Abasat Mirzaei (iD) ${ }^{2, *}$ \\ ${ }^{1}$ School of Health and Management, Islamic Azad University, Tehran Medical Sciences, Tehran, Iran \\ ${ }^{2}$ Health Economics Policy Research Center, Tehran Medical Sciences, Islamic Azad University, Tehran, Iran \\ "Corresponding author: Department of Health Services Management, Faculty of Health, Tehran University of Medical Sciences, Islamic Azad University, Tehran Iran. Email: \\ amacademic@yahoo.com
}

Received 2021 May 12; Revised 2021 July 17; Accepted 2021 August 23.

\begin{abstract}
Context: One of the most important sciences in the tourism industry, which has numerous financial and social benefits, is health and medical tourism. The health tourism industry is an organized trip out of the living environment to maintain, promote, or restore the health of the mind and body of an individual through medical intervention.

Evidence Acquisition: Firstly, 80 articles were identified in different sources. After removing duplicate copies, the number of articles relevant to the study title reached 58. After reviewing the abstracts or full-texts, 35 articles were included in the study based on defined criteria.

Results: The gradual growth of medical tourism has numerous economic and social benefits for both the host community and guests. If medical tourism grows, numerous economic sectors will be directly and indirectly affected, providing ground for social cohesion and integration. The health sector is a critical sector for the development of countries in terms of income and employment, including numerous sub-departments, such as hospitals, medical devices, and clinical trials. Coastal tourism and natural resources are also crucial in terms of income and employment.

Conclusions: Factors affecting medical and health tourism include medical travel agencies, the Internet and social media, political and economic conditions, commitment to post discharge services, regulatory standards, price transparency, confidentiality of patient medical records, and care costs. Medical issues are related to travel legal issues, residence and flight visas, quality and credibility of health care, and specialty of physician's credentials.
\end{abstract}

Keywords: Medical Tourism, Health Tourism, Middle East, Tourism

\section{Context}

The health tourism industry is an organized trip out of the living environment to maintain, promote, or restore the health of the mind and body of an individual through medical intervention. For this reason, different countries have joined the health tourism services market (1). Today, medical and health tourism has become a lucrative and competitive industry (2). When individuals decide to travel to another country for medical services, they are affected by various stimuli (i.e., pressure and traction). The stress factor is more related to the countries and recipients of services; however, another factor is more related to the hair and health system of countries encouraging patients in other countries. It can be said that these factors affect countries and international tourism and have made some countries, such as Thailand, Singapore, and India, have a better position in the international health tourism market than other Asian countries (3).

In recent years, traveling to another country to receive medical services has reached the middle class. Toward the end of the twentieth century, wealthy individuals living in developing countries used the health care services of developed countries that provided better services than their own country; nevertheless, in the last century, the international circulation of the sick began to change. Findings turn to developing countries for cheaper and higherquality service. Moreover, health tourism is expanding in developing countries and even in third world countries (4) and has led many countries to use their existing capacity to grow and prosper in the health tourism industry.

About 11 million individuals traveled to other countries in 2015 to receive health and medical services, and the revenue was $\$ 439$ billion and is projected to reach \$3 trillion by 2025 (5). This has led countries to build infrastructure to maximize their potential share of the medical tourism 
market. In some Asian countries, this industry is relatively new, and for the first time, private hospitals looking for alternative sources of income have turned to this industry (6). However, most countries are trying to improve themselves globally and make large investments in this sector. In the Middle East, the countries of the Persian Gulf are also looking for health tourism and globalization. However, they are not immune to recent tensions in the region. This study aimed to express the perspectives and study the factors affecting the development of health and medical tourism in the Middle East and indicate the importance and popularity of medical tourism.

\section{Evidence Acquisition}

This narrative review examined published English and Persian studies during 2010 - 2020 in ISI, Google Scholar, Scopus, Web of Science, and SID databases, which were collected, reviewed and then compared. At this point, a systematic review was used to search the database. The inclusion criteria for entering the review process were the use of the basic words of the study title and similar studies, completeness and existence of the text of the extracted articles about Iran and different Middle Eastern countries (e.g., Turkey, Saudi Arabia, Jordan, United Arab Emirates [UAE], Egypt, and Kuwait), English or Persian language, quantitative and qualitative methods of research, and relevance of topics to tourism in the field of health. The exclusion criteria were studies for which only an abstract was available, studies that were just case reports, and duplicate studies. Keywords to search included "Tourism”, "Medical Tourism", and "Health Tourism" and their English equivalents, specifically "Medical Tourism" in the country with health tourism. The full texts of the articles and their results sections were extracted, and studies were summarized and reported after reviewing the findings of the extracted articles. Firstly, 80 articles were identified in different sources. After removing duplicate copies, the number of articles related to the study title reached 58. After reviewing the abstracts or full-texts, 35 articles were included in the study based on the defined criteria.

\section{Results}

One of the consequences of world globalization has been an increasing trend in health tourism. Health tourism plays an important role in the development of sustainable tourism by reducing seasonality and diversifying tourism services as a whole. The investigation of scientific studies shows that in the field of health and medical tourism in different countries, due to the importance of the subject, several studies have been conducted in recent years. Most studies are related to Turkey, Iran, UAE, and Saudi Arabia and are descriptive and analytical. A limited number of studies have been performed in other countries, and even some of these countries have studied the quality and application of medical tourism services in their neighboring countries.

The findings of this study showed that medical tourism is rapidly expanding worldwide. More than 50 countries around the world have introduced medical tourism as a national industry. Since 2016, the share of health tourism in developing and underdeveloped countries has varied; However, Tourism revenue in developed and underdeveloped countries is $\$ 62$ billion. Furthermore, the most important result of all this study showed that most countries are starting to work in a specific field and are known to,

Such as Singapore and the Republic of Korea is one of the best examples of the treatment of cancer. In 2016, the number of international trips in the field of health and medical tourism in the world was about 11 million, with 4 million individuals, according to the announcement (Internationale Tourismus-Börse) (7). It is closely related to the number of international travels.

A large part of the leading tourism industry is related to spa tourism, followed by medical tourism and rehabilitation. It can be said that 3.4 million individuals have traveled to receive medical services. Additionally, this demand is increasing day by day. Various factors have been expressed in different countries, the most important of which can be access to cheap and quality medical services, desire to have a long and healthy life, and type of health insurance. Moreover, in addition to receiving health services, having a variety of holidays, access to higher technologies, access to professional services and specialties, and better treatment of chronic diseases related to the weather are among the things that can be mentioned. Furthermore, in the case of Iran, regarding financial issues at this time, this field is very limited, and with strategies, such as increasing the knowledge of hospital staff and attracting physicians with better and related specialties, this industry can be expanded (8).

Studies performed in Iran, especially in Yazd province, showed a relationship between the type of equipment and the quality of treatment, which is important in attracting tourists. Adequate workforce, lack of information system, and reduced marketing have affected the aforementioned issue, along with the favorable climate of health tourism and the abundance of specialists (9). In addition, it is required to note the great and appropriate coordination between government and the private sector (10). In some cases, such as Yemen, Sudan, and Libya, the inexperience of physicians has led individuals to other countries to seek 
better health care. It is necessary to share knowledge and technologies related to health (11). Even religion may influence the choice of destination. Numerous Muslim families prioritize Muslim countries for infertility services (12). In the case of Saudi Arabia, the ability to convince tourists that health care in the region is of reliable quality is one of the most important barriers to medical tourism. In this regard, reputable international agencies are seeking to certify the quality and safety of global patients to overcome the aforementioned barrier (13).

According to reports in Jordan in 2010, approximately the country health sector tourists came from Libya (29\%), Palestine (16\%), Sudan (12\%), and neighboring and Arabicspeaking countries (7\%). Jordan, with annual revenue of $\$ 1$ billion has also grown by about 10\% of foreign patients each year (14). In 2014, a field study entitled "The Impact of Tourism Medicine on Jordan's National Economy” was statistically conducted. The aforementioned study showed a significant relationship between medical tourism and the Jordanian economy. In the aforementioned study, satisfaction with medical tourism in Jordan was assessed as "factors affecting tourists", and the results showed that Jordan has special attractions, such as water, and a variety of weather (especially hot winters) and conditions enabling tourists to use medical resorts in different places throughout the year. In addition to these features, Jordan can attract tourists from other countries due to its geographical location (15).

. According to statistics, Turkey has the most advanced eye hospitals in the world, with one of the largest vision clinics in the world in Istanbul. Turkey also specializes in cosmetic surgery, rhinoplasty, abdominoplasty, and dermatology. Turkey is also known worldwide for its advanced hair transplant techniques, including direct hair transplants. The reason for this is the high quality of operations provided at a competitive rate. According to the daily news of Hurriyet, the main reasons for choosing Turkey as a medical destination include reputable Joint Commission International (JCI) medical centers and equipped hospitals, high quality of services and health technologies, competitive prices, hospitality, and culture, geographical location, and tourism infrastructure. Another advantage is that Turkey has access to more than 70 countries without a visa, and citizens of more than 110 countries can enter the country without a visa. Moreover, Turley is only 2-3 h away from major cities in Europe and the Middle East (16).

In the case of the UAE, it can be said that Dubai is the largest city in the country, which makes every effort to compete with other countries, including Turkey, and to achieve this, it should be able to attract further domestic and foreign investment to improve the medical tourism industry. Dubai should also overcome economic obstacles, such as the high cost of health services and the lack of experienced and skilled physicians with the cooperation between the government and planning (17). Although the health industry in developing countries has rapidly improved in recent years, the price of health services is meager compared to developed countries. On the other hand, price differences and costs, including medical costs (e.g., hospital, medicine, and testing), tour costs (e.g., hotels and expenses), costs of transportation within the city, and travel expenses (e.g., visiting places of pilgrimage and entertainment) as important factors, lead individuals to medical tourism destinations in countries under development.

Recent developments in the healthcare industry have expanded the price range of healthcare services among countries. Iran, with its special climatic and religious conditions, the existence of a common religion with neighboring countries, and better security than neighboring countries, has been able to attract health and medical tourists. Due to the cultural, religious, and linguistic proximity of some border cities with neighboring countries, instead of investing in the expansion of this industry in metropolitan areas, it is necessary to increase the quality of medical equipment and services. Furthermore, areas with desirable natural attractions can be suitable for medical tourism from neighboring countries. Iran, due to its advanced clinics and hospitals, such as Shahid Sadoughi Infertility Treatment Center in Yazd, Kidney, and Liver Transplant Center in Shiraz, Dental and Dialysis Centers in Mashhad, and Cardiac Surgery Centers and Plastic Surgery and Eye Centers in Tehran, has high capacities (18).

Medical tourism in Saudi Arabia is making good progress compared to its Middle Eastern counterparts. Due to the wealth and luxuries of this oil-rich country, medical facilities are regarded as the accurate reflection of the quality and high class (19). Saudi Arabia, unlike many of its competitors in medical tourism, has advanced technology and infrastructure to maintain its market and is stricter in the pharmaceutical sector than the US Food and Drug Administration. The quality of caring in Saudi Arabia meets the US standards. Saudi Arabia can become an attractive medical tourism destination because there are more than 1 billion Muslims in the world. Approximately 5 million Muslims from all over the world travel to Saudi Arabia to perform Hajj and Umrah. Both Mecca and Medina naturally attract millions of Muslims worldwide, which can boost medical tourism. Saudi Arabia's health expenditures accounted for 5\% of its gross domestic product in 2009, compared to those reported for other Middle Eastern countries, with Iraq having the highest health expenditures at 9\% and Bahrain at 2.5\% (20).

International relations are very important factors in choosing a country for medical and health tourism. Saudi 
Arabia can be a destination for medical tourists due to its advanced infrastructure in the field of information technology, such as remote care systems, for diabetics. Saudi Arabia also has highly skilled physicians in specific surgical fields, such as brain and endoscopy. All the factors together have made Saudi Arabia a good place in health and medical tourism. Most of Saudi Arabia's medical tourists are from the UAE, Yemen, Kuwait, and Syria. Medical tourists from Africa come to Saudi Arabia for obstetrics and gynecology services. Obtaining a visa for this country is undesirable. There is not enough information about health and e-health tourists, although there are numerous milestones in this regard. Patients seeking medical care from Saudi Arabia should seek help with planning, booking hotels, and obtaining medical visas. Moreover, with the advent of medical tourism in Saudi Arabia's neighbors, Saudi Arabia should have a well-structured marketing plan.

In Egypt, the most important action in the health tourism industry is a project called “Tour n' Cure" launched by the Ministry of Health, the Ministry of Tourism, and the Ministry of Aviation for hepatitis C patients provide hepatitis $\mathrm{C}$ drugs at affordable price. Tour n' Cure consists of medicine and tourism, and with this initiative, the Egyptian government hopes to attract medical tourists to Egypt. Health tourism in Egypt, similar to other countries, has its pros and cons. Most negative points are related to management in this field, such as the lack of knowledge of the world about this country and its services, lack of coherent educational planning, low-quality services, and lack of skilled physicians. Egypt also has a great location and good infrastructure (21).

Developing countries do not have much desire and competition for medical trips due to financial burden and psychological damage, except in case of necessity and facing a lack of health care in their country, such as Yemen (22).

In the UAE, Dubai is the most populous city located on the southern shores of the Persian Gulf. Dubai is currently recognized as a health tourism destination in the field of health care and medical services (23). This is due to the reasonable cost of services, the ability to speak the international language of staff, and the speed of receiving treatment. The Dubai government attaches great importance to health care and, due to limited oil reserves, has targeted high levels of medical tourism and health services to achieve economic growth. Among the countries in the southern part of Iran, Oman and Dubai are the most considered medical tourism destinations. These countries still face challenges related to shortages of health care personnel, especially nursing, lack of health management programs facing treatment, and human resources. In Turkey in 2015, most of the patients in the medical tourism group were from Libya, and most of the patients in the healthcare group were from Germany. In general, Antalya and Mugla are considered important health and medical tourism cities in Turkey due to their brands, healthcare tourism infrastructure, and accessible transportation options. A slight decrease in tourism in Antalya and Mugla is important for both cities due to the reduction in the number of services in the field of health care and tourism (24).

Turkey ranks as 44th in Travel and Tourism Competitiveness 2017 report on 136 economies. In terms of health and hygiene, Turkey is placed 64th among 139 surveyed countries with a score of 5.4. The variables in which Turkey has a high score, such as price competitiveness, health and hygiene, tourist service infrastructure, and air transport infrastructure, are very important indicators for medical tourism (25). Turkey is the second in the world with the number of accredited health institutions with $48 \mathrm{JCI}$ accredited hospitals. Transportation to Turkey is very easy and economical. Turkey's numerous thermal springs offer the ultimate relaxation, spa, and medicinal experience. The country is the perfect gateway for tourists searching for psychological and physical well-being. From the tourism aspect, Turkey has a lot of cultural, historical, and natural places and beaches. Turkey has made great strides in developing its medical tourism sector by implementing policies. Turkey's national policies boost healthcare tourism. For the attainment of a good level of physical infrastructure and physician competence both in the public and private sectors, Turkey has been working to improve a legal framework (26).

\section{Conclusions}

The Middle East's share of medical tourism in the world and its income, compared to those of Europe, America, Asia, and the Pacific, are about 5 and 4\%, respectively, regarded as low. One of the problems is the insecure situation in the region. It seems that travelers from farther countries than the inhabitants of a neighboring country and region are affected by such events and do not have a good image of the region. Medical tourism has many economic and social benefits. If medical tourism grows, numerous economic sectors will be directly and indirectly affected and provide a sound basis for social coordination and integration. The health sector, in terms of income and employment, is a very important sector for developing countries, which includes many subsectors, such as hospitals, medical devices, and clinical trials. In addition, coastal tourism and natural resources are essential in terms of income and employment. And factors affecting health and medical tourism include medical travel agencies, the Internet and social media, political and economic 
conditions, ensuring commitment to post-discharge services, regulatory standards, price transparency, confidentiality of patient medical records and costs. He mentioned medical care, legal issues related to travel, residence and flight visas, quality of services and the doctor's credit specialization.

Saudi Arabia can become the hub of the health tourism industry due to its up-to-date infrastructure and modern and convenient facilities. However, Saudi Arabia should have the motivation, initiative, and time planning for the industry. relaxation services.

The most important finding of the present study is that medical tourism in Saudi Arabia is influenced by the religion factor and makes individuals choose their destination to use medical and psychological relaxation services. The most effective factors in slowing down the growth of the health industry in Saudi Arabia are Saudi immigration laws are relatively strict.

Iran does not have a good position in the health tourism industry, and the most important factor can be the inadequate infrastructure and history of ineffective treatment in the health system (27).

Turkey has the potential to be one of the largest medical tourism centers globally due to its reputable organizations, highly qualified and educated physicians, modern infrastructure, technology, geographical and climatic features, and natural and historical beauties. Turkey is currently making progress with the joint support of the government and the private sector to provide high-quality and low-cost medical services to its citizens and medical tourists. The Ministry of Health of the Republic of Turkey attaches great importance to the accreditation of public and private health organizations. Today, Turkey has implemented more promotional measures than in the past to introduce itself as a medical tourism center; however, to achieve the desired results, these developments should continue, and sustainable medical tourism management should be achieved.

Jordan's geographical and multi-cultural location, rapid services and performance, advanced medical facilities, hot springs, and natural resorts have led to the rapid development of healthcare tourism in Jordan. However, competition with other countries (e.g., Turkey, Egypt, and the UAE) is also growing.

Dubai is one of the most famous modern cities that has been able to well compete in the global market not only in the field of health and medical tourism but also in all sectors. In this regard, the most important factor is Dubai's emergence and modernization in numerous fields.

Egypt has a traditional health care system with skilled and specialized physicians. One of the strengths of the health system in Egypt is the numerous private service cen- ters looking to invest in Egypt. A lack of timely planning and clear vision is one of the most significant weaknesses of the medical tourism industry in Egypt. Poor marketing practices to compete with the medical tourism sector among competitors could be a threat to Egypt in this regard.

This study showed that medical tourism in Iran is rapidly growing and is supported by the government. However, it still lags behind regional rivals, such as Jordan and Turkey. For the attraction of valuable customers from rich countries, Iran should improve its business environment and infrastructure and provide a strong political, legal, and social environment. Iran should also make efforts to connect the health care industry to the tourism industry and use new communication and marketing technologies

\section{Footnotes}

Authors' Contribution: Study concept and design: F.H and A.M; Acquisition of the data: F.H and A.M; Analysis and interpretation of the data: F.H and A.M; Drafting of the manuscript: F.H and A.M; Critical revision of the manuscript for important intellectual content: F.H and A.M; Statistical analysis: F.H and A.M; Administrative, technical, and material support: F.H and A.M; Study supervision: F.H and A.M.

Conflict of Interests: The authors declare that there is no conflict of interest.

Funding/Support: There is no funding/support for this study.

\section{References}

1. Carrera PM, Bridges JF. Globalization and healthcare: Understanding health and medical tourism. Expert Rev Pharmacoecon Outcomes Res. 2006;6(4):447-54. doi: 10.1586/14737167.6.4.447. [PubMed: 20528514].

2. Khan MJ, Chelliah S, Haron MS. Medical tourism destination image formation process: A conceptual model. Int J Healthc Manag. 2016;9(2):134-43. doi:10.1080/20479700.2016.1142046.

3. Lautier M. International trade of health services: Global trends and local impact. Health Policy. 2014;118(1):105-13. doi: 10.1016/j.healthpol.2014.07.004. [PubMed: 25063193].

4. Ahmed Z, Yeasmeen F. First world healthcare by third world provider: Position of Bangladesh. J Health Sci Res. 2016;1(2):29. doi: $10.18311 /$ jhsr/2016/v1/i2/4597.

5. Keckley PH, Underwood HR. Medical tourism: Consumers in search of value. Deloitte Center for Health Solutions. 2015;5(2):214-854.

6. Horowitz MD, California J. Globalization of the healthcare market. Med Tour Med Gen Med. 2016;33(13).

7. Lagiewski R, Myers W. Medical tourism: Perspectives and applications for destination development. Med Tour Digit Media Libr. 2008.

8. Mirfakhradini H, Mirfakhradini F, Sadr Bafghi M. Investigating rate of iatric tourisms' satisfaction and prioritizing the effective factors on it via Fuzzy TOPSIS approach.J Shahid Sadoughi Univ Med Sci Heal Serv. 2013;20(5):668-78. 
9. Noori GR, Taghizadeh Z, Shirani Z. The role of Iran in Islamic world medical tourism with emphasis on nature therapy: Functions, challenges, and strategies. Q Geogr J Tour. 2012;1(3):1-19.

10. Ebrahim AH, Ganguli S. Strategic priorities for exploiting Bahrain's medical tourism potential. J Place Manag Dev. 2017;10(1):45-60. doi: 10.1108/jpmd-03-2016-0011.

11. Kim S, Lee J, Jung J. Assessment of medical tourism development in Korea for the achievement of competitive advantages. Asia Pac J Tour Res. 2013;18(5):421-45. doi: 10.1080/10941665.2012.658416.

12. Ramamonjiarivelo Z, Martin DS, Martin WS. The determinants of medical tourism intentions: Applying the theory of planned behavior. Health Mark Q. 2015;32(2):165-79. doi: 10.1080/07359683.2015.1033934. [PubMed: 26075544].

13. Middle East Healthcare News. Saudi Arabia witnesses growth in medical tourism" Middle East Healthcare News. 2010. Available from: http: //blog.ictforhealth.com/2010/04/.

14. Khan S, Alam MS. Kingdom of Saudi Arabia: A potential destination for medical tourism. J Taibah Univ Med Sci. 2014;9(4):257-62. doi: 10.1016/j.jtumed.2014.01.007.

15. Kumar DS, Purani K. Model specification issues in PLS-SEM: Illustrating linear and non-linear models in hospitality services context. $J$ Hosp Tour Technol. 2018;9(3):338-53. doi:10.1108/jhtt-09-2017-0105.

16. Saadatnia F, Mehregan MR. Determining and prioritizing factors affecting to increase customers attraction of medical tourism from the perspective of Arabic countries (Case study: Iran-Mashhad Razavi Hospital). Int J Mark Stud. 2014;6(3). doi: 10.5539/ijms.v6n3p155.

17. Al-Talabani H, Kilic H, Ozturen A, Qasim SO. Advancing medical tourism in the United Arab Emirates: Toward a sustainable health care system. Sustainability. 2019;11(1):230. doi: 10.3390/su11010230.

18. Alkadi K, Roudsari A. TeMaD system: Telecare for managing diabetes in Saudi Arabia. Enabling Health Healthc ICT. 2013;183:57.

19. Mainil T, Van Loon F, Dinnie K, Botterill D, Platenkamp V, Meulemans H. Transnational health care: From a global terminology towards transnational health region development. Health Policy. 2012;108(1):37-44. doi: 10.1016/j.healthpol.2012.08.002. [PubMed: 22939046].

20. Ganji SH, Kashyap ML, Kamanna VS. Niacin inhibits fat accumulation, oxidative stress, and inflammatory cytokine IL-8 in cultured hepatocytes: Impact on non-alcoholic fatty liver disease. Metabolism. 2015;64(9):982-90. doi: 10.1016/j.metabol.2015.05.002. [PubMed: 26024755].

21. Mays L. Opportunities and challenges. Integr Urban Water Manag Arid Semi-Arid Reg. 2014:71-4. doi: 10.1201/9781482266207.

22. Sina A. Law in Medicine. Business Logistics. 2007:283.

23. Weber AS. Sustainable tourism in extreme environment: lessons from desert regions. Int Sci Conf Tour South East Eur. 2013;2:421.

24. Morakabati Y. Tourism in the Middle East: Conflicts, crises and economic diversification, some critical issues. Int JTour. 2013;15(4):375-87. doi: 10.1002/jtr.1882.

25. Kllavuz E. Medical tourism competition: The case of Turkey. Int J Health Manag Tourism. 2018:42-58. doi:10.31201/ijhmt.372364.

26. JCI-Accredited Organizations. Joint commission international. JCI-Accredited Organizations; 2021. Available from: https: //www.jointcommissioninternational.org/aboutjci/accreditedorganizations.

27. Gholami M, Keshtvarz Hesam Abadi AM, Milady S, Gholami M. A sys tematic review of the factors affecting the growth of medical tourism in Iran. Int J Travel Med Glob Health. 2020;8(1):1-12. doi: 10.34172/ijtmgh.2020.01. 